\title{
emeraldinsight
}

\section{Assembly Automation}

Aerodynamic feeding systems: an example for changeable technology

Thomas Frädrich, Julia Pachow-Frauenhofer, Fiege Torsten, Peter Nyhuis,

\section{Article information:}

To cite this document:

Thomas Frädrich, Julia Pachow-Frauenhofer, Fiege Torsten, Peter Nyhuis, (2011) "Aerodynamic feeding systems: an example for changeable technology", Assembly Automation, Vol. 31 Issue: 1, pp.47-52, https://doi.org/10.1108/01445151111104164

Permanent link to this document:

https://doi.org/10.1108/01445151111104164

Downloaded on: 01 February 2018, At: 04:38 (PT)

References: this document contains references to 34 other documents.

To copy this document: permissions@emeraldinsight.com

The fulltext of this document has been downloaded 296 times since 2011*

\section{Users who downloaded this article also downloaded:}

(2013),"Fully flexible assembly systems (F-FAS): a new concept in flexible automation", Assembly Automation, Vol. 33 Iss 1 pp. 8-21 <a href="https://doi.org/10.1108/01445151311294603">https://doi.org/10.1108/01445151311294603</a>

(1997),"Designing a parts feeding system for maximum flexibility", Assembly Automation, Vol. 17 Iss 2 pp. 116-121<a href="https://doi.org/10.1108/01445159710171329">https://doi.org/10.1108/01445159710171329</a>

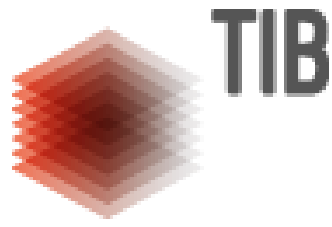

Access to this document was granted through an Emerald subscription provided by emerald-srm:271967 []

\section{For Authors}

If you would like to write for this, or any other Emerald publication, then please use our Emerald for Authors service information about how to choose which publication to write for and submission guidelines are available for all. Please visit www. emeral dinsight. com/ authors for more information.

\section{About Emerald www.emeraldinsight.com}

Emerald is a global publisher linking research and practice to the benefit of society. The company manages a portfolio of more than 290 journals and over 2,350 books and book series volumes, as well as providing an extensive range of online products and additional customer resources and services.

Emerald is both COUNTER 4 and TRANSFER compliant. The organization is a partner of the Committee on Publication Ethics (COPE) and also works with Portico and the LOCKSS initiative for digital archive preservation.

*Related content and download information correct at time of download. 


\title{
Research article
}

\section{Aerodynamic feeding systems: an example for changeable technology}

\author{
Thomas Frädrich, Fulia Pachow-Frauenhofer, Fiege Torsten and Peter Nyhuis \\ Institute of Production Systems and Logistics, Leibniz University of Hanover, Garbsen, Germany
}

\begin{abstract}
Purpose - The purpose of this paper is to transfer the idea of changeability to a concrete technical application.

Design/methodology/approach - Based on the definition of changeability on a factory level, a transformation of the five change enablers specified therein for the work station level using the example of an aerodynamic feeding system takes place in this paper.

Findings - The observed aerodynamic feeding system can be determined as changeable.

Practical implications - Changeable systems are able to react with low effort to exterior influences, e.g. of the market, and thus represent a considerable competitive advantage.

Originality/value - The new element in this paper is the observation of change enablers on the work station level. This point of view enables the concrete figuration of changeable technical systems.
\end{abstract}

Keywords Aerodynamics, Feeding devices, Production management, Factories

Paper type Research paper

\section{Introduction}

The circumstances under which the industrially producing companies act have changed strongly within the last years - the worldwide markets react to external influences in increasingly shorter time frames. Established approaches of the last decades, such as "computer-based production" or "flexible production" can no longer meet up with this trend. This is documented by the study "changeable production systems" carried out by the Institute of Production Systems and Logistics (IFA) of the Leibniz University of Hannover and other leading research institutes in production technique with well-known enterprises. This study was subsidized by the Federal Ministry for Education and Research (BMBF). A matching result of the study is, on the one hand, that currently there is no other possibility for a company to react to external influences other than flexibility. On the other hand, the study showed that the scientific construct of changeability as it is currently intensively discussed in the German research landscape, is theoretically apt to resolve these deficits, but it is not concrete and tangible enough to find application in companies. The central idea of changeability consists in designing production system in such a manner that a pre-developed solution space can be activated with low investments. Yet these mostly provide theoretical concepts about this range of topics or go into the planning and evaluation approaches, only seldom can one find technical

The current issue and full text archive of this journal is available at www.emeraldinsight.com/0144-5154.htm

Assembly Automation

31/1 (2011) 47-52

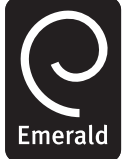

(C) Emerald Group Publishing Limited [ISSN 0144-5154] [DOI 10.1108/01445151111104164] examples for changeable solutions. That is, where this paper sets off. The aim is to demonstrate that aerodynamic feeding systems, as developed at the IFA, are an example for a changeable system. In the following, the subject of changeability will be shortly introduced at first as well as its understanding as it forms the basis of this paper. Subsequently, feeding systems in general and especially aerodynamic systems will be described. The main part of this paper will set about depicting the changeability of aerodynamic feeding systems. The paper will conclude with a summary and an outlook.

\section{Changeability}

The turbulent environment requires a production system to be rapidly adaptable to altered conditions. On this note, in today's practice, production systems are only designed flexibly in many cases (De Toni and Tonchia, 1998; Wiendahl et al., 2007; ElMaraghy and Wiendahl, 2008). If a production system is flexible, it is able (for example, in the case of a higher output demand) to customize fast and without additive invest inside of the narrow corridor. But the change drivers are very versatile nowadays and the direction as well as the force of change are no longer easily foreseeable (Pachow-Frauenhofer et al., 2008). As a reaction to the initially weak changing impulses, so far production-related solutions have been developed whose implementation often took several years. One example is the modularly structured standard assembly cell "Mobi-Cell" by BMW (2005). To prepare a production system for all possible changes is not feasible, to start off with from the economic point of view. Owing to this reason it is necessary to design a system, which enables a dynamic adaptation of the production system. This is where the main idea of changeability sets off. In the literature, there are different definitions of changeability to be found (Schuh et al., 2004; Spath and Scholtz, 2007). ElMaraghy and Wiendahl define changeability 
as a characteristic of a production system which enables an economic, anticipatory adaptation of all factory elements and processes on all factory levels at an early stage (Wiendahl et al., 2007; ElMaraghy and Wiendahl, 2008). On the basis of the definition of ElMaraghy and Wiendahl (Wiendahl et al., 2007; ElMaraghy and Wiendahl, 2008), Nyhuis et al. describe changeability as in the following (Pachow-Frauenhofer et al., 2008; Heinen et al., 2008).

Changeability is recognized as the potential by which fast adaptation is enabled within narrow corridors, concerning the organization and the techniques, with low investment. The changeable production system is planned on the displacement of the barrier of the corridors. The utilization of this potential is carried out only when needed. An additional option made possible by changeability is the contraction option where it would be possible, for example, to downgrade the level of automation if it is feasible as it would also be favourable concerning the environment. Changeability is to be understood as a system attribute and has to consider its internal and external interdependences. Thus, changeability is superordinate to flexibility (Wiendahl, 2005). Since changeable production systems act in dynamic environments, they do not have to be planned and kept in constant operation just once. Instead, a process has to be activated, which, following a basic analysis, offers creative solutions, that are continuously adjusted to the environmental requirements and restructured if necessary. The differences between flexibility and changeability are made clear in Figure 1.

The prestudy shows that in practice various approaches exist to react to unforeseeable turbulences not only in the carried out case studies in well-known companies but also in an extensive literature research (Bredow, 2008; Wörn, 2008). Numerous approaches for flexible but also adaptive or agile production systems are described in the literature inter alia (Koren et al., 1999; Koren, 2006; Abele et al., 2008; Lotter and Wiendahl, 2008). Yet none of these approaches is sufficient to design the companies in a long-term responsive manner, since all these approaches only enable a reaction within pre-planned solutions, but not a reaction to unplanned turbulences. Yet the theoretical construct of "changeability" finds no or only minor application in practice so far (Pachow-Frauenhofer et al., 2008). A public discourse additionally showed that a large deficit lies in the measurement and evaluation of changeability. Nowadays, same as for the approach of flexibility (De Toni and Tonchia, 1998), it is impossible to measure changeability and its benefit (Browne et al., 1984; Brill and Mandelbaum, 1989; Nyhuis, 2008).

Cisek et al. (2002) describes in that production has five options to react to exterior changes. These are lot size, product, quality, time and costs. A flexible system possesses the ability

\section{Figure 1 Definition of changeability}

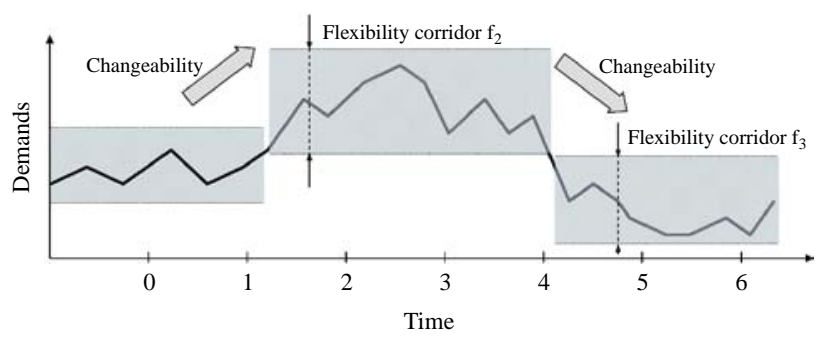

Source: Zäh et al. (2005) of adaptation concerning one of these factors whereas a changeable system possesses the ability to adapt the system concerning several of these factors.

A production system consists of different objects that can be designed in an individually changeable manner. For this, they have to possess certain characteristics to enable a change process. These are called change enablers. Wiendahl et al. describe change enablers on the factory level (Hernández Morales, 2003; Wiendahl et al., 2005):

- Scalability. Technical, spatial and staff permeability (extendibility and reducibility), e.g. flexible working time model.

- Modularity. Standardised, serviceable units or elements, e.g. Plug \& produce-modules.

- Compatibility. Interconnectability concerning material, information, media and energy, e.g. standardised software interfaces.

- Universality. Dimensioning and designing of various requirements concerning a product or technology, e.g. variation flexibility.

- Mobility. Spatially unlimited mobility of objects, e.g. machines on reels.

That means that the systems which possess these change enablers are considered as changeable. Yet it is to be considered that not all objects can or have to possess all change enablers. This is to be investigated in case of need.

\section{Feeding system}

The feeding serves as a technical system of linking value-adding processes in the forefront of the assembly and the assembly station itself. Such as the process-logically advanced transport of components, the feeding itself is not a value-adding process.

The mostly used feeding system is the vibratory bowl feeder (VBF). Boothroyd, for example, produced a catalogue for an ample spectrum of workpieces for the feeding with VBFs, containing several general solutions and a large number of special characteristics of typical workpieces (Boothroyd, 1984). van der Stappen et al. (2002) have also regarded various part geometries in different feeding systems. Despite all these investigations, it is impossible to examine vibration feeders without experimental investigations of the behaviour of real pieces in the feeding process. The reason for this lies in the chaotic physical processes of the micro throw. Hongler, for example, discovered that pieces follow chaotic rules during the orientation process (Hongler, 1994). Yet the pieces had a very simple geometry and the focus of the work lay on the general dynamic pieces behaviour. Others investigated the natural resting of pieces in the VBF (Ngoi et al., 1997), yet again only for cubic geometries. It is thus almost impossible to establish general behavioural rules for pieces in industrial applications.

The progress in the computer industry and picture processing has lead to the fact that feeding systems are increasingly equipped with cameras for flexible systems (Perks, 2006; Braggins, 2006; Sorensen and Stringham, 1999). Yet this generally also has complex systems as a consequence which need an additional handling installation, mostly robots, to implement the results of the picture processing. An aerodynamic procedure which was developed at the IFA uses standard singularisation systems, such as VBFs or centrifugal bowl feeders (CBFs) in connection with air nozzles as barriers for the singularisation of workpieces in combination with an 
active aerodynamic orienting device as an out of bowl tooling. The pieces are individually handed over as partial strings to aerodynamic actuators (out of the bowl) which can be combined according to the requirement of the collocation task. The actuators can be created from the aerodynamic orientation processes described in the following.

There are two aerodynamic orientation processes which use two workpiece characteristics each (Figure 2). First, there is the possibility of an axial orientation of the workpieces. In that case they slide down an inclined plane which can be adjusted and into which an air nozzle is integrated. Together, with the air nozzle, the plane establishes the aerodynamic actuator, which actively puts the workpieces into the desired position. For this purpose, the position of the center of gravity and the geometry of the workpieces are used. Since the pieces pass the nozzle at a certain speed on the inclined plane, the permanently flowing air from the nozzle creates an impulse according to the orientation of the piece (for example, center of gravity at the front or back) which turns the wrongly oriented workpieces and maintains the correctly oriented ones (Wiendahl and Rybarczyk, 2003).

The second process enables a radial orientation. The position of the center of gravity or special aerodynamic characteristics of geometry can also be used in this case. The radial orientation by means of the position of the center of gravity is carried out on an air cushion that the piece settles down on almost without friction and with the center of gravity downwards after having "floated" down onto the air. The geometrical characteristics in turn are used on the inclined plane with integrated air nozzles whose impulse either turns the pieces or not, according to their position.

The orientation of the pieces is carried out actively, i.e. the workpieces are put into the desired position by means of the air flow. The air flows applied here are also to be regarded as orienting devices which IFA has been developing since the beginning of the 1990s and not as the equally long known aerodynamic blades as they are used in passive operations (Müller-Kramp, 1992; Wiendahl et al., 1999; Jaksic and Maul, 2001). The output performance of a production plant with active orientation will rise accordingly depending on the number of stable positions that a workpiece can occupy (Boothroyd, 2005). For example, if there are two-piece positions, the output with active orientation will rise by 100 per cent. The aerodynamic orientation itself works without sensor technology or image processing.

Figure 3 shows a feeding system with two actuators: an inclined plane and an air cushion. In each of these actuators, the degree of orderliness of the workpiece is increased until finally only singular workpieces in selected workpiece positions are to be found. In this case, the singularisation of the workpieces is carried out by a CBF which is filled by a bunker system. In industrial application, the orientation is followed by the checkup of the workpiece orientation by means of a camera system so as to ensure that exclusively correctly oriented and qualitatively faultless workpieces reach the following process. Figure 3 shows the modular construction of the system which enables a simple exchange of the single modules.

\section{Changeability of aerodynamic feeding systems}

In Part 2, the five change enablers for factory level described in the literature have already been depicted briefly. A system is changeable if it possesses the necessary change enablers. For the evaluation of the changeability of the aerodynamic system as described in Chapter 3 its constitutive criteria concerning the existence of change enablers are to be examined in the following.

Scalability mainly determines spatial degrees of liberty of concerning extension, growth but also shrinkage in factory planning. The enabler is also called breathability and for technical systems can be interpreted such that in this case the spatial degrees of liberty refer to the amount processed in the system. In the first instance, an aerodynamic actuator for the orientation of components is merely subject to physical limits, namely laws of nature. The number of workpieces which can slide along the inclined plane is the same as can be individually handed over as a string of pieces. The limitation thus lies with the singularisation system, which hands over this string of pieces to the aerodynamic actuator. That means that the

Figure $\mathbf{2}$ Aerodynamic orientation process

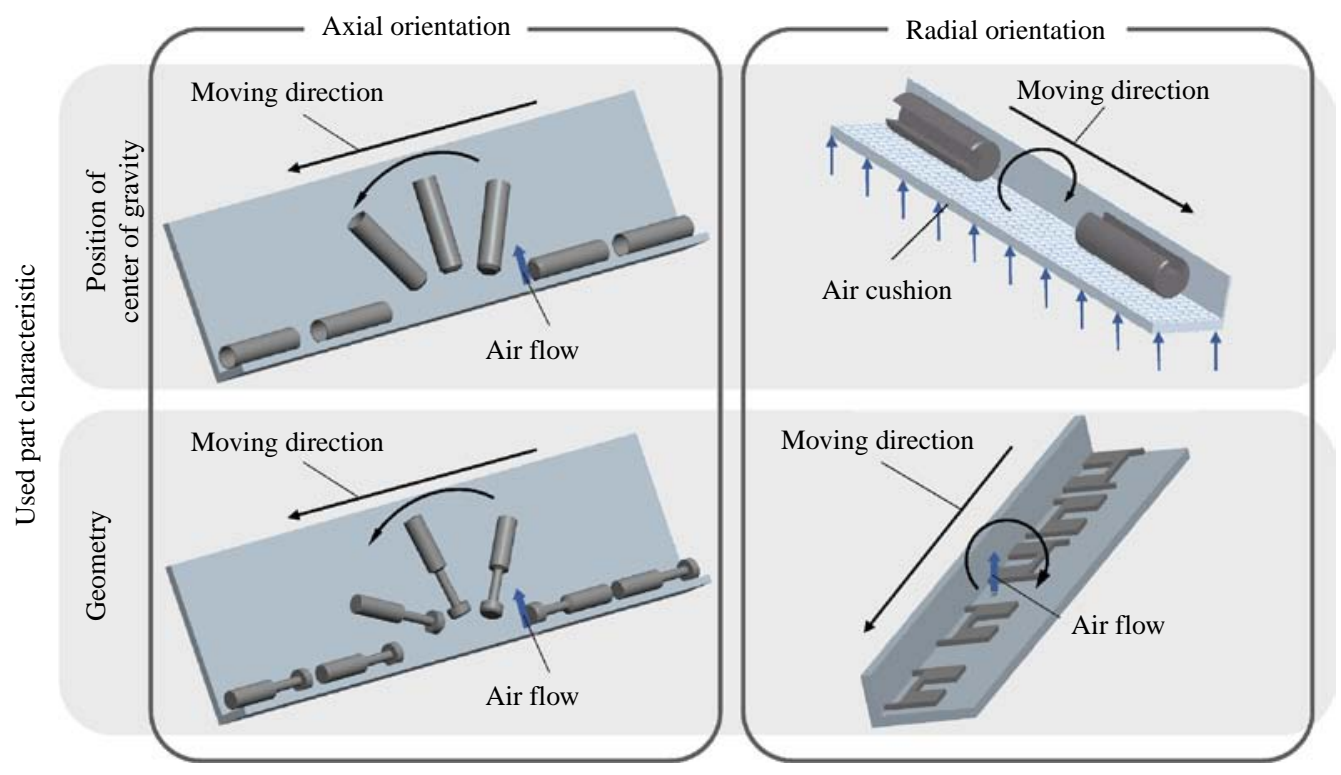


Figure 3 Aerodynamic feeding system

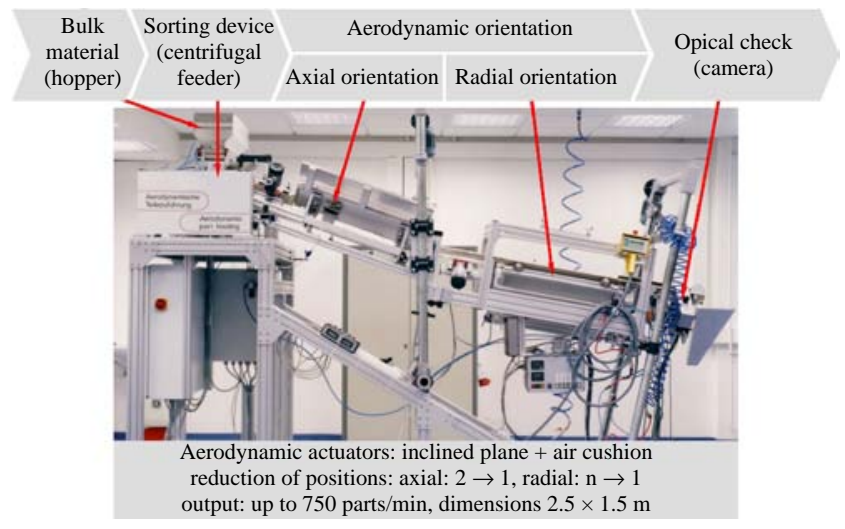

aerodynamic actuator demonstrates a very large flexibility corridor (Figure 1) but does not fulfill the change enabler "scalability". Yet an aerodynamic feeding system consisting of aerodynamic actuators and further modules does fulfill this change enabler. Such a system is scalable concerning the amount processed in the system. The choice of the singularisation system (VBF or CBF) can actually change the output performance, for example.

Modularity is based on the idea of standardised elements so that the exchange of modules only has partial effects (e.g. shutdowns) on the change object or its environment. So modules are autonomously acting entities, which ensure a high degree of compatibility among each other. Aerodynamic actuators are self-sufficiently functioning entities or modules. They can be introduced individually or in combination with each other for the orientation of components together with a preposed singularisation system.

Compatibility is tightly connected with modularity but not equivalent to it. By means of standardised interfaces, compatibility enables a low effort drop-down resp. integration of modules. Aerodynamic actuators consist of gliding zones where work pieces are lead past air nozzles or on air cushions. They enable a continuous process which bears no special requirements towards the interfaces. So as to reach a defined speed when the pieces encounter the actuator, a simple transport band is sufficient which is generally independent of the geometry of the components.

Universality represents the characteristic of objects to meet the diverse tasks, requirements, aims or functions. Technical systems have generally been constructed for a precise aim resp. on the basis of certain functional principles. For example, by now, modern five-axis rotating/milling centers can produce geometries with almost any degree of complexity but they are not able to change the production process - it always remains with the cutting basic principle. Aerodynamic actuators were developed for the orientation of small parts and remain within this spectrum. Yet within this range, the procedures are apt for the most diverse parts whose position of center of gravity or special aerodynamic characteristics allow an aerodynamic orientation. That also means that by the application of air flows they are independent from the outer contour of the components which stands in contrast with the majority of standard orientation procedures (e.g. mechanical harassments in the VBF). That makes the same actuator applicable for different pieces after only minor adaptations of the parameters.
Mobility ensures the local, unlimited mobility of objects in a factory. That means that when the factory itself is designed changeably, so that, for example, the media necessary for the operation of the facility can be put at disposition at any place in the factory at a low effort, the facility itself simply has to stand on wheels so as to fulfill the requirements of this enabler. An aerodynamic feeding device consisting of a singularisation system and one or two aerodynamic actuators is suitable in any case, concerning the measurements as well as the weight, to be mobilised on wheels.

So the five change enablers originating from the factory planning are given in the case of the aerodynamic feeding technology and enable a variation of two of the five requirements for the adaptation of production to exterior changes presented by Cisek (see Chapter 2) for the moment. The lot size and the product, that is the component to be fed, can be adapted to exterior conditions by means of aerodynamic feeding systems with a low effort. The lot size can be selected through the choice of the singularisation. The orientation of the component takes place independently of the geometry. If one observes the feeding systems in an environment with short product life cycles, two further requirements can be influenced, namely costs and time. Owing to the aptitude of aerodynamic feeding systems for different component geometries described in the paragraph "universality", it is not necessary to acquire new conventional feeding technologies in the case of a product change. Over a longer term and several product changes, the corresponding purchasing costs can be saved. Yet this does not only concern the costs, the time investment for the construction and production of the conventional system is also omitted. Even more importantly than the time saving for the supplier, it is to be considered that the expenses for initiating operation with the user are reduced. Owing to his familiarity with the aerodynamic feeding, he saves time during its installation and thus reduces complexity from starting up his new product at the same time. Even the fifth reaction requirement, the quality, can be improved by using the aerodynamic feeding technology. It is an active procedure for the orientation of work pieces and, therefore, has the advantage that the components have to go through the feeding process only once. In the case of passive procedures, pieces are sorted out several times before they are coincidentally on hand in the desired orientation. This bears a higher risk of damage for the work pieces.

Figure 4 exemplifies several pieces with different geometries which can be oriented with the aerodynamic feeding system

Figure 4 Examples for aerodynamically oriented pieces

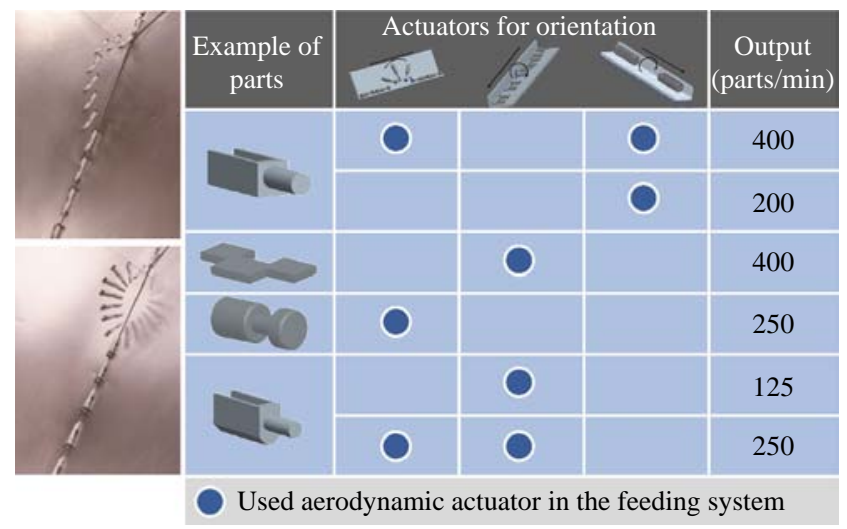


described in Part 3. For this purpose, the aerodynamic actuators have simply been adapted to the existing system. The displayed pieces are oriented by using the actuator or the combination of two actuators to different degrees. For example, the uppermost pieces can be completely oriented to one position with two actuators (output: 400 pieces $/ \mathrm{min}$ ). Yet the same piece can also be partly oriented with an actuator in the feeding system (output: 200 pieces/min). This example vividly makes the changeability of aerodynamic feeding systems clear.

\section{Summary}

To begin with, this paper briefly introduced the term "changeability" and its definition as well as the aerodynamic feeding as a technical system. The following discussion of the system on the basis of change enablers allows for the following conclusion: aerodynamic feeding systems are changeable. They feature all the change enablers described in the factory planning and can thus themselves be called changeable as technical systems with their physical limitations. The big advantage of aerodynamic systems compared to conventional ones lies in their "universality", that means their ability to be suitable for different pieces equally. Owing to the extensively workpiece-neutral modules of the aerodynamic feeding systems and the low-wear and reproducible processes they can be applied for the most diverse products over a long period of time. This can represent a considerable cost advantage compared with conventional systems, especially in the case of short product life cycles. This cost advantage of changeable systems compared with conventional feeding systems is to be demonstrated in further studies.

\section{References}

Abele, E., Kuhn, S. and Hueske, B. (2008), "Overall equipment flexibility", ZWF-Zeitschrift für wirtschaftlichen Fabrikbetrieb, Vol. 103 No. 5, pp. 322-7.

BMW (2005), Annual Report 2005, Kapitel: Welcher Weg führt zum Erfolg?, available at: www.bmwgroup.com/d/nav/ index.html?./0_0_www_bmwgroup_com/home/home.html \&source $=$ overview (accessed November 23, 2009).

Boothroyd, G. (1984), Handbook of Feeding and Orienting Techniques for Small Parts, Catalogue, Department of Mechanical Engineering, University of Massachusetts, Amherst, MA.

Boothroyd, G. (2005), Assembly Automation and Product Design, Taylor \& Francis, Boca Raton, FL.

Braggins, D. (2006), "Vision today for assembly automation", Assemblv Automation, Vol. 26 No. 3, pp. 181-3.

Bredow, M. (2008), "Wandlungsfähigkeit in der grundlagenorientierten Fachliteratur", in Nyhuis, P., Reinhart, G. and Abele, E. (Eds), Wandlungsfähige Produktionssysteme, Produktionstechnisches Zentrum GmbH, Garbsen, pp. 34-40.

Brill, P.H. and Mandelbaum, M. (1989), "On measures of flexibility in manufacturing systems", International fournal of Production Research, Vol. 27 No. 5, pp. 747-56.

Browne, J., Dubois, D., Rathmill, K., Sethi, S.P. and Stecke, K.E. (1984), "Classification of flexible manufacturing systems", The FMS Magazine, Vol. 2, pp. 116-7.

Cisek, R., Habicht, C. and Neise, P. (2002), "Gestaltung wandlungsfähiger Produktionssysteme", Zeitschrift für
Volume $31 \cdot$ Number $1 \cdot 2011 \cdot 47-52$

wirtschaftlichen Fabrikbetrieb (ZWF), Vol. 97 No. 9, pp. 441-5.

De Toni, A. and Tonchia, S. (1998), "Manufacturing flexibility: a literature review", International fournal of Production Research, Vol. 36 No. 6, pp. 1587-617.

ElMaraghy, H. and Wiendahl, H.-P. (2008), "Changeability an introduction", in ElMaraghy, H. (Ed.), Changeabel and Reconfigurable Manufacturing Systems, Springer, London, pp. 3-24.

Heinen, T., Rimpau, c. and Wörn, A. (2008), Wandlungsfähigkeit als Ziel der Produktionssystemgestaltung, PZH Produktionstechnisches Zentrum GmbH, Garbsen.

Hernández Morales, R. (2003), "Systematik der Wandlungsfähigkeit in der Fabrikplanung”, Diss. Leibniz Universität Hannover, VDI Verlag GmbH, Düsseldorf.

Hongler, M.-O. (1994), Chaotic and Stochastic Behaviour in Automatic Production Lines, Springer, Berlin.

Jaksic, N.I. and Maul, G.P. (2001), "Development of a model for part reorientation in vibratory bowl feeders with active air jet tooling", Robotics and Computer Integrated Manufacturing, Vol. 17, pp. 145-9.

Koren, Y. (2006), "General RMS characteristic. Comparison with dedicated and flexible systems", in Dashenko, A. (Ed.), Reconfigurable Manufacturing Sustems and Transformable Factories, Springer, Berlin, pp. 27-45.

Koren, Y., Heisel, U., Jovane, F., Moriwaki, T., Pritschow, G., Ulsoy, G. and van Brussel, H. (1999), "Reconfigurable manufacturing systems. A keynote paper", Annals of CIRP, Vol. 48 No. 2, pp. 527-40.

Lotter, B. and Wiendahl, H.-P. (2008), "Changeable and reconfigurable assembly systems", in ElMaraghy, H. (Ed.), Changeable and Reconfigurable Manufacturing Systems, Springer, London, pp. 127-46.

Müller-Kramp, T. (1992), "Flexibles Ordnen von Werkstücken”, Dissertation Universität Hannover, Fortschritt-Berichte VDI, Reihe 2 No. 239, VDI, Düsseldorf.

Ngoi, B.K.A., Lim, L.E.N. and Ee, J.T. (1997), “Analysis of natural resting aspects of parts in a vibratory bowl feeder validation of 'drop test'", Advanced Manufacturing Technologv, Vol. 13 No. 4, pp. 300-10.

Nyhuis, P. (2008), "Öffentlicher Diskurs", in Nyhuis, P., Reinhart, G. and Abele, E. (Eds), Wandlungsfähige Produktionssysteme - Heute die Industrie von Morgen gestalten, Produktionstechnisches Zentrum GmbH, Garbsen, pp. 102-45.

Pachow-Frauenhofer, J., Frädrich, T. and Nyhuis, P. (2008), "Changeable assembly systems and supplier equipment", in ElMaraghy, H. (Ed.), paper presented at the 2nd CIRP Conference on Assembly Technologies and Systems (CATS), Toronto.

Perks, A. (2006), "Advanced vision guided robotics provide future-proof flexible automation", Assemblv Automation, Vol. 26 No. 3, pp. 216-20.

Schuh, G., Harre, J., Gottschalk, S. and Kampker, A. (2004), "Design for Changeability (DFC) - Das richtige Maß an Wandlungsfähigkeit finden", wt Werkstattstechnik online, Vol. 94 No. 4, pp. 100-6.

Sorensen, S. and Stringham, R. (1999), "Vision guided flexible feeding made easy", Industrial Robot, Vol. 26 No. 2, pp. 99-104. 
Spath, D. and Scholtz, O. (2007), "Wandlungsfähigkeit für eine wirtschaftliche Montage in Deutschland", Industrie Management, Vol. 23 No. 2, pp. 61-4.

van der Stappen, A.F., Berretty, R.-P., Goldberg, K. and Overmars, M.H. et al. (2002), "Geometry and Part Feeding”, in Hager, G.D. (Ed.), Sensor Based Intelligent Robots, LNCS 2238, Springer, Berlin, pp. 259-81.

Wiendahl, H.-P. (2005), "Die wandlungsfähige Fabrik: Konzept und Beispiel", in Engel, K.H. (Ed.), Praxishandbuch Betriebsleiter, WEKA MEDIA, Kissing.

Wiendahl, H.-P. and Rybarczyk, A. (2003), "Using air streams for part feeding systems - innovative and reliable solutions for orientation and transport", fournal of Materials Processing Technologv, Vol. 138 Nos 1-3, pp. 189-95.

Wiendahl, H.-P., Lorenz, B. and Rybarczyk, A. (1999), "Using airstreams for part feeding technology", Annals of the German Academic Society for Production Engineering (WGP), Vol. 2 No. 7.

Wiendahl, H.-P., Nofen, D., Klußmann, J.H. and Breitenbach, F. (2005), Planung modularer Fabriken, Carl Hanser, München Wien.

Wiendahl, H.-P., ElMaraghy, H., Nyhuis, P., Zäh, M.F., Wiendahl, H.-H., Duffle, N. and Brieke, M. (2007), "Changeable manufacturing - classification, design and operation", Annals of the CIRP, Vol. 56 No. 2, pp. 1-26.

Wörn, A. (2008), "Wandlungsfähigkeit in der unternehmensnahen Fachliteratur", in Nyhuis, P., Reinhart, G. and Abele, E. (Eds), Wandlungsfähige Produktionssysteme, Produktionstechnisches Zentrum GmbH, pp. 41-6.
Zäh, M.F., Moeller, N. and Vogl, W. (2005), "Symbiosis of changeable and virtual production", in Zaeh, M.F. (Ed.), 1st International Conference on Changeable, Agile, Reconfigurable and Virtual Production (CARV 2005), München 22-23 September, Utz, pp. 3-10.

\section{About the authors}

Thomas Frädrich is based at the Institute of Production Systems and Logistics, Leibniz University of Hanover. Thomas Frädrich is the corresponding author and can be contacted at: fraedrich@ifa.uni-hannover.de

Julia Pachow-Frauenhofer is based at the Institute of Production Systems and Logistics, Leibniz University of Hanover.

Fiege Torsten is based at the Institute of Production Systems and Logistics, Leibniz University of Hanover.

Peter Nyhuis, born in 1957, studied Mechanical Engineering at the Leibniz Universität Hannover and, subsequently, worked as Research Associate at the Institute of Production Systems and Logistics (IFA). After receiving his doctorate in Mechanical Engineering he habilitated before he became Executive Manager in the field of supply chain management for the electronic and mechanical engineering industry. Since 2003, he heads the Institute of Production Systems and Logistics (IFA) at the Leibniz Universität Hannover. In 2008, he became member of the management board of the IPH - Institute of Integrated Production Hannover (non-profit limited company).

To purchase reprints of this article please e-mail: reprints@emeraldinsight.com

Or visit our web site for further details: www.emeraldinsight.com/reprints 


\section{This article has been cited by:}

1. Giulio Rosati, Fabio Oscari, Luca Barbazza, Maurizio Faccio. 2016. Throughput maximization and buffer design of robotized flexible production systems with feeder renewals and priority rules. The International Journal of Advanced Manufacturing Technology 85:1-4, 891-907. [CrossRef]

2. Giulio Rosati, Maurizio Faccio, Luca Barbazza, Aldo Rossi. 2015. Hybrid fexible assembly systems (H-FAS): bridging the gap between traditional and fully flexible assembly systems. The International Journal of Advanced Manufacturing Technology 81:5-8, 1289-1301. [CrossRef]

3. Jan Busch, Maurice Schmidt, Lukas Richter, Peter Nyhuis. 2014. Eine selbsteinstellende Zuführeinrichtung. ZWF Zeitschrift für wirtscbaftlichen Fabrikbetrieb 109:7-8, 512-515. [CrossRef]

4. Giulio RosatiDepartment of Management and Engineering, University of Padua, Padova, Italy Maurizio FaccioDepartment of Management and Engineering, University of Padua, Padova, Italy Andrea CarliDepartment of Management and Engineering, University of Padua, Padova, Italy Aldo RossiDepartment of Management and Engineering, University of Padua, Padova, Italy. 2013. Fully flexible assembly systems (F-FAS): a new concept in flexible automation. Assembly Automation 33:1, 8-21. [Abstract] [Full Text] [PDF] 